\title{
Synthesis and Characterization of Cyclic Cationic Polymer and its Anti-corrosion Property for Low Carbon Steel in 15\% HCl Solution
}

\author{
Shamsuddeen A. Haladu ${ }^{1}$, Saviour A. Umoren ${ }^{2, *}$, Shaikh A. Ali ${ }^{3}$, Moses M. Solomon ${ }^{4}$ \\ ${ }^{1}$ Department Basic Sciences, College of Engineering, University of Dammam, Saudi Arabia \\ ${ }^{2}$ Centre of Research Excellence in Corrosion, Research Institute, King Fahd University of Petroleum \\ and Minerals, Dhahran 31261, Saudi Arabia \\ ${ }^{3}$ Department of Chemistry, King Fahd University of Petroleum \& Minerals, Dhahran 31261, Saudi \\ Arabia \\ ${ }^{4}$ Corrosion Research Laboratory, Department of Mechanical Engineering, Faculty of Engineering, \\ Duzce University, 81620 Duzce, Turkey \\ *Email: umoren@kfupm.edu.sa
}

doi: $10.20964 / 2017.10 .57$

Received: 28 April 2017 / Accepted: 6 August 2017 / Published: 12 September 2017

A new cyclic cationic polymer (CCP) bearing bis-3-phosphorylpropyl pendants was synthesized using chain-growth polymerization technique with ammonium persulphate (APS) as initiator. The synthesized polymer was characterized using FTIR, ${ }^{1} \mathrm{H}$ NMR and ${ }^{13} \mathrm{C}$ NMR techniques. The corrosion inhibition performance evaluation of the newly synthesized polymer for low carbon steel in $15 \% \mathrm{HCl}$ was carried out using weight loss measurements at $25-60{ }^{\circ} \mathrm{C}$, electrochemical impedance spectroscopy (EIS), potentiodynamic polarization (PDP) and linear polarization resistance (LPR) techniques. The effect of addition of small amounts $(5 \mathrm{mM})$ of $\mathrm{ZnCl}_{2}$ and $\mathrm{KI}$ on the corrosion inhibition performance of CCP was also assessed. Results obtained indicate that CCP acts as an inhibitor for low carbon steel corrosion in the aggressive acid environment. Inhibition efficiency increased slightly with increasing $\mathrm{CCP}$ concentration. Also, inhibition efficiency was found to decrease with increase in temperature. Addition of $\mathrm{ZnCl}_{2}$ and KI to CCP has profound effect on the corrosion inhibition performance, which was more pronounced with $\mathrm{KI}$ compared to $\mathrm{ZnCl}_{2}$. Corrosion protection efficiency followed the trend $\mathrm{CCP}+\mathrm{KI}>\mathrm{CCP}+\mathrm{ZnCl}_{2}>\mathrm{CCP}$. The enhanced corrosion inhibition of $\mathrm{CCP}$ on addition of $\mathrm{ZnCl}_{2}$ and $\mathrm{KI}$ is due to synergistic effect as confirmed from the calculated synergistic parameter which was found to be greater than unity. Inhibition of low carbon steel corrosion in $15 \% \mathrm{HCl}$ occurs by virtue of physical adsorption of CCP onto the steel surface which can be approximated by Langmuir adsorption isotherm model. The SEM/EDS images confirm the adsorption of CCP to form protective film on the low carbon steel surface.

Keywords: Polymer; Hydrochloric acid; steel; Acid corrosion; Corrosion inhibition; Synergism 


\section{FULL TEXT}

(C) 2017 The Authors. Published by ESG (www.electrochemsci.org). This article is an open access article distributed under the terms and conditions of the Creative Commons Attribution license (http://creativecommons.org/licenses/by/4.0/). 